\title{
Domestic aeroallergen exposures among infants in an English town
}

\author{
W. Atkinson, J. Harris, P. Mills, S. Moffat, C. White, O. Lynch, M. Jones, \\ P. Cullinan, A.J. Newman Taylor
}

\begin{abstract}
Domestic aeroallergen exposures among infants in an English town. W. Atkinson, J. Harris, P. Mills, S. Moffat, C. White, O. Lynch, M. Jones, P. Cullinan, A.J. Newman Taylor. (C)ERS Journals Ltd 1999.

ABSTRACT: A multicentre, prospective cohort study of childhood asthma was established in three European countries; the purpose of the project is the examination of factors which modify the relationship between allergen exposure in infant life and subsequent atopy and asthma.

Dust samples were collected from the homes of 643 infants in a single town in the UK (the first cohort) and assayed for house dust mites (Der $p$ 1) and cat allergen (Fel $d$ 1) concentrations by enzyme-linked immunosorbent assay. A questionnaire with potential relevance to the development of atopy and asthma was completed.

A wide variation in exposure to both allergens was observed. Carpeted, doubleglazed or damp living rooms, and those sampled in the winter months, had higher levels of Der $p 1$, but these features did not predict Fel $d 1$ concentrations. Measures of high home occupancy were positively related to $\operatorname{Der} p 1$ concentrations; and inversely with levels of $\mathrm{Fel} d \mathrm{~d}$, a finding which could not be explained by cat ownership. Homes in which one or more persons smoked had significantly lower concentrations of Der $p$ 1 , but not $\mathrm{Fel} d \mathrm{~d}$. There were no consistent differences in allergen levels between homes where one or more parent or sibling was either atopic or asthmatic.

These findings indicate complex interactions among domestic, behavioural and seasonal factors and early allergen exposure in British children.

Eur Respir J 1999; 13: 583-589.
\end{abstract}

Childhood asthma in the UK is generally associated with specific sensitization to common aeroallergens, frequently from house dust mites (including $\operatorname{Der} p 1$ ) or cats ( Fel $d$ 1). The incidence of sensitization and asthma may be related to the intensity of exposure to these allergens in early life $[1,2]$. In occupational asthma, which is an informative model, it has been shown that rates of development of specific immunoglobulin (Ig)E and work-related respiratory symptoms are highest soon after first employment and are directly related to the intensity of allergen exposure in this period [3]; similarly, outside the workplace, the incidence of atopy and asthma are highest in the first years of life [4]. The aetiological role of early allergen exposure has been examined in a number of case-control and ecological comparisons but prospective studies are limited in number.

This study was designed specifically to test the hypotheses that the relationships between atopy and asthma and the intensity of allergen exposure during infancy are modified by genetic and concurrent environmental exposures. Cohorts of infants in three different European countries have been assembled and are being followed prospectively through childhood. This paper describes aeroallergen exposures in the homes of the first of these, a cohort of babies born in Ashford, Kent, UK.
Dept of Occupational and Environmental Medicine, Imperial College (National Heart and Lung Institute), London, UK.

Correspondence: P. Cullinan

Dept of Occupational and Environmental Medicine

Imperial College (National Heart and Lung Institute)

1b Manresa Road

London SW3 6LR

UK

Fax: 441713518336

Keywords: Allergen exposure

asthma

atopy

Der $p$

Fel d 1

social class

Received: March 191998

Accepted after revision November 71998

Supported by the Colt Foundation.

Methods

\section{Cohort recruitment}

Ashford is $100 \mathrm{~km}$ south-east of London and $30 \mathrm{~km}$ from the coast, at an altitude of $60 \mathrm{~m}$ above sea level. It is typical of medium-sized towns in the region, with an expanding population of approximately 80,000 people and employment mainly in light industry. Between November 1993 and July 1995 all females presenting for antenatal care at three family medical practices in the town were invited to participate in a prospective study. Six-hundred and sixty-seven (93\% of those eligible) agreed and subsequently gave birth to 643 babies in 635 homes. Eight weeks after the birth, one of three trained nurses visited each home to carry out a variety of exposure measurements, including dust collection for aeroallergen assays.

\section{Dust sampling and extraction}

Dust samples were taken from two sites, the living room floor and the baby's bed, from 618 (97\%) households. A standard household vacuum cleaner (Goblin Rio, 1,000 W; Goblin, Leeds, UK) was used, fitted with $8 \mu \mathrm{m}$ filter paper (Whatman, Maidstone, UK) in an ALK dust trap (ALK, Maidstone, UK) which was washed with soap and warm 
water between each sample. Living room samples were standardized by vacuuming an area of $1 \mathrm{~m}^{2}$ for $3 \mathrm{~min}$. Mattress covers were left in place and the whole bed surface was measured and vacuumed for the same duration. In this way living room carpets from 617 homes and mattresses used by 625 children were sampled.

Exposed filter papers were stored at $-20^{\circ} \mathrm{C}$ in sealed petri dishes until allergen analysis. To obtain fine dust, each sample was sieved through a $355 \mu \mathrm{m}$ mesh sieve, recording weights before and after sieving. Filters were washed overnight at $4{ }^{\circ} \mathrm{C}$ in $3 \mathrm{~mL}$ borate-buffered saline- $0.1 \%$ Tween (pH 8.0) and $2 \mathrm{~mL}$ of this solution was added to 100 $\mathrm{mg}$ of sieved dust. A proportionate amount of buffer was added if the weight of dust was between 50-100 mg, and 1 $\mathrm{mL}$ added to dust weighing $<50 \mathrm{mg}$. The dust samples were constantly rotated at room temperature for $2 \mathrm{~h}$ and the aqueous layer was removed after centrifugation at 1,400 $\times g$ at $4^{\circ} \mathrm{C}$ for $20 \mathrm{~min}$ and stored at $-20^{\circ} \mathrm{C}$. Sieved dust samples from 272 (44\%) living rooms and 541 (87\%) children's beds had a weight $<50 \mathrm{mg}$.

\section{Allergen determination}

Fel $d 1$ and $\operatorname{Der} p 1$ concentrations were determined using an enzyme linked immunosorbent assay (ELISA) as described previously [5]. In brief, microtitre plates (Immulon 2, Dynatech Labs, Billinghurst, UK) were coated overnight with $100 \mu \mathrm{L} 10 \mu \mathrm{g} \cdot \mathrm{mL}^{-1}$ monoclonal antibodies, 5H8 for $\mathrm{Der} p 1$ and 6F9 for Fel $d 1$ (Indoor Biotechnologies, Chester, UK), in $50 \mathrm{mM}$ carbonate buffer $(\mathrm{pH}$ 9.6). Doubling dilutions of UVA 93/03 for Der $p 1$ and UVA 91/01 for Fel $d 1$ (Indoor Biotechnologies) were used to produce control curves, ranging from 0.24 to 250 $\mathrm{ng} \cdot \mathrm{mL}^{-1}$ for Der $p 1$ and 0.02 to $20.0 \mathrm{mU} \cdot \mathrm{mL}^{-1}$ for Fel $d 1$. Standards $\left(100,20\right.$ and $5 \mathrm{ng} \cdot \mathrm{mL}^{-1}$ for Der $p 1$ and $10,2.5$ and $0.31 \mathrm{mU} \cdot \mathrm{mL}^{-1}$ for $\mathrm{Fel} d$ 1) were included in each microtitre plate. Samples were initially assayed undiluted and at dilutions of neat, 1:5, 1:25 and 1:125 and further if necessary. Samples were then incubated at room temperature for $1 \mathrm{~h}$. Following washing, $100 \mu \mathrm{L} 10 \mu \mathrm{g} \cdot \mathrm{mL}^{-1}$ biotinylated antibodies, 4CL for Der $p 1$ and 3E4 for Fel d 1 (Indoor Biotechnologies), were added and plates incubated for a further hour at room temperature. After washing, the ELISA was developed with streptavidin peroxidase (Sigma, Poole, UK) and 2,2'-azido-bis(3-ethylbenz-thiazoline-6-sulphonic acid) (Sigma). The absorbance was read at $405 \mathrm{~nm}$ on a Dynatech MR5000 ELISA reader.

Levels of $\operatorname{Der} p 1$ were undetectable in $65(11 \%)$ of all living room samples and 217 (35\%) of all samples from the child's bed; levels of Fel $d 1$ were undetectable in $20(3 \%)$ of all living room samples and 105 (17\%) of all samples from the child's bed. These were assigned the value of half of the limit of detection, i.e. $2.50 \mathrm{ng} \cdot \mathrm{mL}^{-1}$ for Der $p 1$ and $0.31 \mathrm{mU} \cdot \mathrm{mL}^{-1}$ for Fel $d 1$. There was no relationship between the weight of dust sampled and the probability of there being detectable allergen. Samples obtained from children's mattresses tended to have low total dust weights; therefore, measurements from these are expressed as a proportion of unsieved dust.

\section{Questionnaire and skin testing}

At the time of dust collection, the nurses administered a detailed questionnaire (available from the authors) to each householder. This enquired into a variety of structural features of each home, and also into a number of social, behavioural and health-related characteristics of the household that were of potential relevance to the development of asthma and atopy. Social class was defined by current paternal occupation using the UK Registrar General's 1990 classification. The six categories, ranging from professional occupations (social class I) to unskilled occupations (social class V), group people with similar levels of occupational skill.

Each parent was invited to undergo standard skin-prick tests with extracts of common aeroallergens (Allergopharma, Nottingham, UK) mixed grass pollens (006), cat fur (309) and Dermataphagoides pteronyssinus (725), each with a potency of $50,000 \mathrm{U} \cdot \mathrm{mL}^{-1}$. All but three mothers and $539(87 \%)$ of fathers were tested in this way and were considered to be atopic if one or more prick tests produced a mean weal diameter $3 \mathrm{~mm}$ larger than that of a negative (saline) control.

\section{Statistical methods}

Concentrations of both allergens were log-normally distributed; all analysis was undertaken using log-transformed data and expressed as geometric means (GM) with 95\% confidence intervals (CI). Differences in allergen concentrations between homes were analysed using t-tests and Chi-squared tests for trend and regression analysis. A full model with adjusted p-values was constructed using stepwise selection where all possible predictors were considered

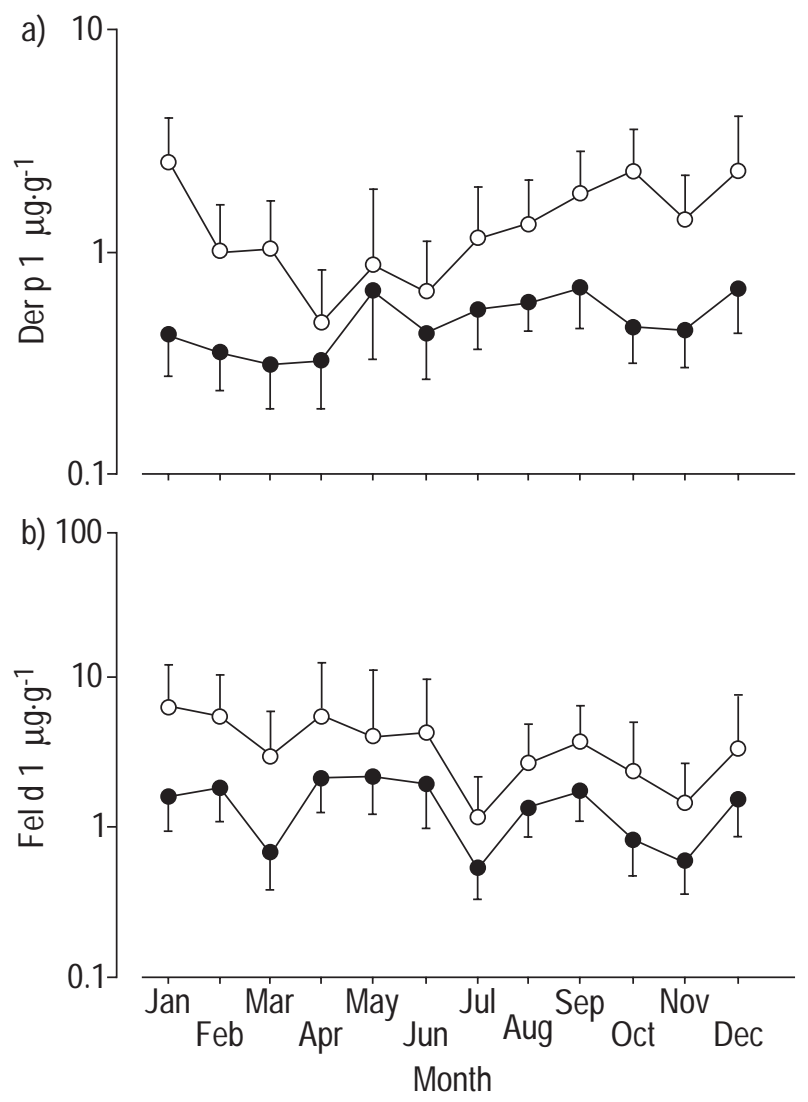

Fig. 1. - Concentrations of a) house dust mite allergen (Der $p 1)$ and b) cat allergen $(\mathrm{Fel} d \mathrm{1}$ ) in living room carpet $(\bigcirc)$ and child's bed $(\bullet)$ by month. Values presented as geometric mean $\pm 95 \%$ confidence interval. 
Table 1. - House dust mite (Der p 1) and cat allergen (Fel d 1) concentrations

\begin{tabular}{lcc}
\hline & Living room & Child's mattress* \\
\hline Der $p 1 \mu \mathrm{g} \cdot \mathrm{g}^{-1}$ & & \\
$\mathrm{n}$ & 616 & 619 \\
$\mathrm{GM}(95 \% \mathrm{CI})$ & $1.4(1.2-1.6)$ & $0.5(0.4-0.6)$ \\
Range & $0.02-385.0$ & $0.002-3168.1$ \\
$>2.0 \mu \mathrm{g} \cdot \mathrm{g}^{-1}(\%)$ & $262(42)$ & $94(15)$ \\
$>10.0 \mu \mathrm{g}^{-1}(\%)$ & $94(15)$ & $21(3)$ \\
$F e l d 1 \mu \mathrm{g} \cdot \mathrm{g}^{-1}$ & & 617 \\
$\mathrm{n}$ & 616 & $1.2(1.0-1.4)$ \\
$\mathrm{GM}(95 \% \mathrm{CI})$ & $3.1(2.6-3.8)$ & $0.003-990.0$ \\
$\mathrm{Range}$ & $0.01-14151.3$ & $121(20)$ \\
$>8.0 \mu \mathrm{g} \cdot \mathrm{g}^{-1}(\%)$ & $186(30)$ & \\
\hline
\end{tabular}

individually for inclusion and remained in the model if they met the $p=0.15$ significance level. All analyses were carried out using SAS software (SAS Institute, Cary, NC, USA).

Before analysis, data on the age of the house and the mattress, and the level of crowding within each home were categorized into two groups on the basis of their distributions; cut-offs were made at approximately the 25 th percentile. Seasons were allocated according to the month of sampling: March-May (spring); June-August (summer); September-November (autumn) and December-February (winter).

The study was approved by the ethics committee of Royal Brompton Hospital and the National Heart and Lung Institute.

\section{Results}

Season

In total, 120 homes were sampled in the spring months, 154 in summer, 195 in autumn and 157 in winter. Concentrations of both allergens fluctuated seasonally, with levels of $\operatorname{Der} p 1$ in the living room higher in the autumn and winter. There was more variation in $\mathrm{Fel} d 1$ concentrations, with a tendency for levels in both the living room and child's bed to be higher in the first half of the year (fig. 1).

There was no relationship between social class and season of birth but, through small variations in the interval between birth and sampling, the season of sampling was associated with the social class of the household. Homes of families in social classes I and II were more likely to be sampled in the autumn and winter months $(61 \%)$, whereas homes of families from social class IV and V were visited more often in the summer and autumn (63\%). Sampling from homes of families in social class III was evenly spread over the year. These differences were statistically significant $(p=0.05)$. There was no indication that the frequency of reported dampness in the home varied over the seasons $\left(c^{2} 1.45, p=0.69\right.$ for living room; $c^{2} 1.21$, $\mathrm{p}=0.75$ for child's bedroom).

\section{Allergen concentrations}

Average levels of both allergens were higher in the living room than in the child's bed (table 1). Ninety-four $(15 \%)$ of the living room samples and $21(3 \%)$ of the child's bed samples had a Der $p 1$ concentration $>10 \mu \mathrm{g} \cdot \mathrm{g}^{-1}$. There were $186(30 \%)$ living room samples and 121 $(20 \%)$ child's bed samples with a Fel $d 1$ concentration $>8$ $\mu \mathrm{g} \cdot \mathrm{g}^{-1}$.

\section{Structural associations}

The concentrations of Der $p 1$ found in the living room samples were significantly higher in homes with fitted carpets, double glazing or visible damp (table 2). Levels of $\mathrm{Fel} d 1$ were significantly higher in newer homes $(\leq 10$ yrs old) and homes that were less crowded ( $>2$ rooms per

Table 2. - Environmental determinants of indoor levels of allergen

\begin{tabular}{|c|c|c|c|c|c|c|}
\hline & $\mathrm{n}$ & $\operatorname{Der} p 1 \mu \mathrm{g} \cdot \mathrm{g}^{-1 *}$ & p-value & $\geq 1 \mathrm{cat}^{\dagger}$ & Fel d $1 \mathrm{mg} \cdot \mathrm{g}^{-1} *$ & p-value \\
\hline \multicolumn{7}{|l|}{ Living room measurements $(n=618)$} \\
\hline "New" house ( $\leq 10$ yrs) & 146 & $1.3(1.0-1.7)$ & 0.56 & $48(33)$ & $4.7(3.1-7.1)$ & 0.05 \\
\hline "Old" house (>10 yrs) & 442 & $1.4(1.2-1.7)$ & & $142(32)$ & $2.9(2.3-3.7)$ & \\
\hline "Low" crowding (>2 rooms per person) & 113 & $1.1(0.8-1.5)$ & 0.15 & $40(35)$ & $7.2(4.4-11.9)$ & $<0.001$ \\
\hline "High" crowding ( $\leq 2$ rooms per person) & 504 & $1.4(1.2-1.7)$ & & $154(31)$ & $2.6(2.1-3.2)$ & \\
\hline Fitted wall-to-wall carpets & 594 & $1.4(1.2-1.6)$ & 0.03 & $188(32)$ & $3.2(2.6-3.9)$ & 0.24 \\
\hline No fitted carpets & 23 & $0.6(0.3-1.0)$ & & $6(26)$ & $1.7(0.7-4.4)$ & \\
\hline Double glazing in living room & 379 & $1.6(1.3-1.9)$ & 0.03 & $113(30)$ & $3.2(2.5-4.1)$ & 0.79 \\
\hline No double glazing & 238 & $1.1(0.9-1.4)$ & & $81(34)$ & $3.0(2.2-4.2)$ & \\
\hline Visible damp in living room & 25 & $4.3(2.2-8.6)$ & 0.002 & $8(32)$ & $2.9(1.2-7.0)$ & 0.86 \\
\hline No visible damp & 592 & $1.3(1.1-1.5)$ & & $186(31)$ & $3.1(2.6-3.9)$ & \\
\hline \multicolumn{7}{|l|}{ Child's bed measurements $(\mathrm{n}=626)$} \\
\hline Plastic mattress & 95 & $0.5(0.3-0.6)$ & 0.78 & $29(31)$ & $0.8(0.5-1.3)$ & 0.03 \\
\hline Other mattress & 494 & $0.5(0.4-0.6)$ & & $165(32)$ & $1.3(1.1-1.6)$ & \\
\hline "New" mattress ( $\leq 1$ month old) & 138 & $0.3(0.3-0.4)$ & $<0.001$ & $44(32)$ & $1.0(0.7-1.4)$ & 0.16 \\
\hline "Old" mattress (>2 months old) & 399 & $0.5(0.5-0.6)$ & & $134(34)$ & $1.3(1.1-1.7)$ & \\
\hline Fitted wall-to-wall carpet & 578 & $0.5(0.4-0.6)$ & 0.88 & $184(32)$ & $1.2(1.0-1.4)$ & 0.56 \\
\hline No fitted carpets & 37 & $0.5(0.3-0.9)$ & & $9(24)$ & $1.0(0.5-1.9)$ & \\
\hline Double glazing in bedroom & 382 & $0.5(0.4-0.6)$ & 0.91 & $112(29)$ & $1.1(0.9-1.4)$ & 0.32 \\
\hline No double glazing & 233 & $0.5(0.4-0.6)$ & & $81(35)$ & $1.3(1.0-1.8)$ & \\
\hline Visible damp in bedroom & 40 & $0.7(0.4-1.2)$ & 0.15 & $13(33)$ & $0.9(0.5-1.7)$ & 0.34 \\
\hline No visible damp & 575 & $0.5(0.4-0.5)$ & & $180(31)$ & $1.2(1.0-1.5)$ & \\
\hline
\end{tabular}

*: Geometric mean $\left(95 \%\right.$ confidence interval); ${ }^{\dagger}$ : n (\%). Der $p$ 1: house dust mite allergen; Fel $d$ 1: cat allergen. 
Table 3. - Behavioural determinants of living room levels of allergen

\begin{tabular}{|c|c|c|c|c|c|c|}
\hline Living room measurements $(\mathrm{n}=626)$ & $\mathrm{n}$ & $\operatorname{Der} p 1 \mu \mathrm{g} \cdot \mathrm{g}^{-1} *$ & $\mathrm{p}$-value & $\geq 1 \mathrm{cat}^{\dagger}$ & Fel d $1 \mu \mathrm{g} \cdot \mathrm{g}^{-1} *$ & p-value \\
\hline \multicolumn{7}{|c|}{ Father's social class based on occupation } \\
\hline I Professional & 40 & $1.7(1.0-2.9)$ & \multirow[t]{7}{*}{0.13} & $17(43)$ & $8.4(3.4-20.5)$ & \multirow[t]{7}{*}{$<0.001$} \\
\hline II Managerial and technical & 121 & $1.5(1.1-2.2)$ & & $43(36)$ & $5.6(3.4-9.2)$ & \\
\hline IIIN Skilled (nonmanual) & 73 & $1.8(1.2-2.8)$ & & $25(34)$ & $4.5(2.5-8.1)$ & \\
\hline IIIM Skilled (manual) & 192 & $1.1(0.9-1.5)$ & & $62(32)$ & $3.0(2.1-4.2)$ & \\
\hline IV Partly skilled & 95 & $1.4(1.0-2.0)$ & & $40(42)$ & $3.1(1.9-5.1)$ & \\
\hline V Unskilled & 29 & $1.0(0.5-1.9)$ & & $2(7)$ & $1.0(0.6-1.7)$ & \\
\hline Other & 75 & $1.4(0.9-2.2)$ & & $8(11)$ & $1.0(0.6-1.7)$ & \\
\hline \multicolumn{7}{|l|}{ Number of older siblings } \\
\hline 0 & 264 & $1.1(0.9-1.3)$ & \multirow[t]{4}{*}{0.05} & $88(33)$ & $4.5(3.3-6.3)$ & \multirow[t]{4}{*}{0.001} \\
\hline 1 & 228 & $1.8(1.4-2.3)$ & & $66(29)$ & $2.8(2.0-3.8)$ & \\
\hline 2 & 94 & $1.3(0.9-2.0)$ & & $31(33)$ & $2.1(1.3-3.3)$ & \\
\hline$\geq 3$ & 39 & $1.7(0.9-3.1)$ & & $12(30)$ & $1.6(0.8-3.5)$ & \\
\hline \multicolumn{7}{|l|}{ Number of people in the home } \\
\hline 2 or 3 & 242 & $1.1(0.9-1.4)$ & \multirow[t]{3}{*}{0.02} & $81(33)$ & $5.1(3.6-7.2)$ & \multirow[t]{3}{*}{$<0.001$} \\
\hline 4 & 233 & $1.6(1.2-2.0)$ & & $67(29)$ & $2.7(2.0-3.7)$ & \\
\hline$\geq 5$ & 149 & $1.7(1.2-2.3)$ & & $49(33)$ & $1.9(1.3-2.8)$ & \\
\hline \multicolumn{7}{|l|}{ Smoker at home } \\
\hline 0 & 383 & $1.7(1.4-2.1)$ & \multirow[t]{2}{*}{0.001} & $135(35)$ & $4.0(3.1-5.3)$ & \multirow[t]{2}{*}{0.003} \\
\hline$\geq 1$ & 242 & $1.0(0.8-1.2)$ & & $62(26)$ & $2.2(1.6-2.9)$ & \\
\hline \multicolumn{7}{|l|}{ Parental history } \\
\hline Asthma & 159 & $1.4(1.0-1.9)$ & \multirow[t]{2}{*}{0.92} & $52(33)$ & $3.0(2.0-4.4)$ & \multirow[t]{2}{*}{0.68} \\
\hline No asthma & 461 & $1.4(1.1-1.6)$ & & $145(31)$ & $3.3(2.6-4.2)$ & \\
\hline
\end{tabular}

*: Geometric mean (95\% confidence interval); ${ }^{\dagger}: \mathrm{n}(\%) .{ }^{\star}:$ This includes unemployed, armed forces and missing information (excluded from regression analysis). Der $p$ 1: house dust mite allergen; Fel $d$ 1: cat allergen.

person). None of the structural features of the room (floor covering, dampness or double glazing) appeared to be associated with the levels of Fel $d 1$.

Older mattresses contained slightly higher concentrations of $\operatorname{Der} p 1$ and $\mathrm{Fel} d$ 1, while plastic mattresses tended to have lower levels of Fel $d 1$ but not Der $p 1$. The characteristics of the room did not appear to be related to the concentrations of allergens found in the child's bed.

\section{Social and behavioural associations}

The number of residents did not differ significantly across the socioeconomic groups (median 4.0 for all social classes). There was a marked increasing trend in smoking among families from lower socioeconomic groups: $21 \%$ of social class I and II homes included a smoker compared with $33 \%$ of social class III and $52 \%$ of social class IV and $\mathrm{V}$ homes $(\mathrm{p}<0.001)$.

Concentrations of Der $p 1$ in both the living rooms and the childrens beds showed a significant increase as the number of residents or the number of older siblings increased; conversely, the concentrations of Fel $d 1$ decreased with more residents or older siblings, with a stronger trend in the living room samples (tables 3 and 4). There was also a striking reduction, across the social classes, in levels of Fel $d 1$ on the floors and beds. Thirty-seven per cent of social class I and II families owned a cat, compared with $33 \%$ of social class III families and $34 \%$ of social class IV and V families ( $p=0.16$, Chi-squared test for trend). Families from higher socioeconomic groups tended to own more cats: $15 \%$ of social class I and II families and social class III families owned $\geq 2$ cats, compared with $11 \%$ of social class IV and V families $(\mathrm{p}=0.42)$.

Homes with at least one resident smoker had lower levels of both allergens in the living room (tables 3 and 4). The relationship with Der $p 1$ was observed in homes where any adult was a smoker, whereas the decreased levels of Fel $d 1$ were exclusively found in homes where the mother smoked, GM $1.7 \mu \mathrm{g} \cdot \mathrm{g}^{-1}(1.1-2.6)$ in homes where the mother was a smoker compared to $3.7 \mu \mathrm{g} \cdot \mathrm{g}^{-1}$ (3.0-4.6) in homes where the mother was a nonsmoker, $(\mathrm{p}=0.002)$. Households with $\geq 1$ smokers were also significantly less likely to keep a pet cat (26\% versus $35 \%$ cats owner; $\mathrm{p}=0.02$ ).

Allergen levels were not significantly different in homes where at least one of the parents had a history of asthma (tables 3 and 4). Two-hundred and twenty-nine infants had one older sibling, $30(13 \%)$ of whom had a reported history of asthma. Levels of both allergens were similar in these homes.

Levels of $\mathrm{Fel} d 1$ were higher in the living rooms of homes where at least one of the parents was atopic. Mothers with a positive skin-prick test to cat fur were more likely to keep a cat $(43 \%)$ than those with a negative skin test $(30 \%)(\mathrm{p}=0.02)$. There was no such relationship with fathers: $33 \%$ of both those who had a positive skin test to cat fur and those who had a negative skin test owned a cat.

The ownership of cats was similar for those families where one or both parents had a history of asthma and those with no history of asthma (33\% versus $32 \%$ owned cats; $\mathrm{p}=0.80)$. There was no evidence to suggest differences in the floor covering in the living room or child's bedroom: $97 \%$ of homes with parental history of asthma had fitted carpets in the living room and $94 \%$ had fitted carpets in the child's bedroom, compared with $96 \%$ and $93 \%$ in homes with no parental history of asthma; $p=0.36$ and 0.63 , respectively.

\section{Cat ownership}

There was a marked increase in levels of Fel $d 1$ as the number of cats within the home increased (fig. 2). For each 
Table 4. - Behavioural determinants of child's bed levels of allergen

\begin{tabular}{|c|c|c|c|c|c|c|}
\hline Child's bed measurements $(n=626)$ & $\mathrm{n}$ & $\operatorname{Der} p 1 \mu \mathrm{g} \cdot \mathrm{g}^{-1} *$ & p-value & $\geq 1 \mathrm{cat}^{\dagger}$ & Fel $d 1 \mu \mathrm{g} \cdot \mathrm{g}^{-1} *$ & $\mathrm{p}$-value \\
\hline \multicolumn{7}{|c|}{ Father's social class based on occupation } \\
\hline I Professional & 40 & $0.6(0.3-1.0)$ & \multirow[t]{7}{*}{0.83} & $17(43)$ & $2.1(1.0-4.1)$ & \multirow[t]{7}{*}{0.004} \\
\hline II Managerial and technical & 120 & $0.5(0.4-0.6)$ & & $41(34)$ & $1.8(1.2-2.6)$ & \\
\hline IIIN Skilled (nonmanual) & 71 & $0.6(0.4-0.8)$ & & $23(32)$ & $1.4(0.8-2.4)$ & \\
\hline IIIM Skilled (manual) & 190 & $0.4(0.3-0.4)$ & & $62(33)$ & $1.0(0.8-1.3)$ & \\
\hline IV Partly skilled & 95 & $0.6(0.4-0.9)$ & & $40(42)$ & $1.6(1.1-2.3)$ & \\
\hline V Unskilled & 29 & $0.5(0.3-0.8)$ & & $2(7)$ & $0.4(0.2-0.8)$ & \\
\hline Other & 74 & $0.7(0.4-1.0)$ & & $9(12)$ & $0.7(0.5-1.1)$ & \\
\hline \multicolumn{7}{|l|}{ Number of older siblings } \\
\hline 0 & 263 & $0.4(0.3-0.4)$ & \multirow[t]{4}{*}{0.002} & $87(33)$ & $1.5(1.1-1.9)$ & \multirow[t]{4}{*}{0.08} \\
\hline 1 & 225 & $0.6(0.5-0.7)$ & & $64(28)$ & $1.1(0.8-1.4)$ & \\
\hline 2 & 93 & $0.7(0.5-0.9)$ & & $31(33)$ & $1.1(0.7-1.6)$ & \\
\hline$\geq 3$ & 38 & $0.6(0.4-1.1)$ & & $12(32)$ & $1.0(0.5-1.9)$ & \\
\hline \multicolumn{7}{|l|}{ Number of people in the home } \\
\hline 2 or 3 & 242 & $0.4(0.3-0.4)$ & \multirow[t]{3}{*}{$<0.001$} & $80(33)$ & $1.6(1.3-2.1)$ & \multirow[t]{3}{*}{$<0.001$} \\
\hline 4 & 231 & $0.6(0.5-0.7)$ & & $67(29)$ & $1.1(0.8-1.4)$ & \\
\hline$\geq 5$ & 146 & $0.6(0.5-0.8)$ & & $47(32)$ & $0.9(0.6-1.3)$ & \\
\hline \multicolumn{7}{|l|}{ Smoker at home } \\
\hline 0 & 380 & $0.5(0.4-0.6)$ & \multirow[t]{2}{*}{0.43} & $131(34)$ & $1.3(1.0-1.6)$ & \multirow[t]{2}{*}{0.47} \\
\hline$\geq 1$ & 239 & $0.5(0.4-0.6)$ & & $63(26)$ & $1.1(0.9-1.4)$ & \\
\hline \multicolumn{7}{|l|}{ Parental history } \\
\hline Asthma & 158 & $0.5(0.4-0.6)$ & \multirow[t]{2}{*}{0.70} & $51(32)$ & $1.3(0.9-1.8)$ & \multirow[t]{2}{*}{0.66} \\
\hline No asthma & 456 & $0.5(0.4-0.6)$ & & $143(31)$ & $1.2(1.0-1.4)$ & \\
\hline
\end{tabular}

*: Geometric mean (95\% confidence interval); ${ }^{\dagger}: \mathrm{n}(\%) .{ }^{\dagger}$ : This includes unemployed, armed forces and missing information (excluded from regression analysis). Der $p$ 1: house dust mite allergen; Fel $d$ 1: cat allergen.

year that a cat had lived in the home there was a small but significant increase in total Fel $d 1$ of $0.07 \mu \mathrm{g} \cdot \mathrm{g}^{-1}(\mathrm{p}<$ 0.001 ). Levels of Fel $d 1$ associated with short-haired cats were similar for males and females, with an estimated increase in allergen of $2.78 \mu \mathrm{g} \cdot \mathrm{g}^{-1}$ for each male shorthaired cat and $3.09 \mu \mathrm{g} \cdot \mathrm{g}^{-1}$ for each female; levels associated with long-haired cats were much higher for male than female cats (an additional $4.75 \mu \mathrm{g} \cdot \mathrm{g}^{-1}$ and $1.76 \mu \mathrm{g} \cdot \mathrm{g}^{-1}$ respectively). This interaction between the sex of the cat and fur type was statistically significant $(\mathrm{p}=0.02)$.

Fel $d 1$ was detectable in virtually all $(404 ; 96 \%)$ of the living room floors from homes without cats; and, in the same homes, $78 \%$ of children's mattresses. The equivalent figures for cat-owning homes were $99 \%$ and $94 \%$.

\section{Multiple regressions}

All variables listed in tables $2-5$, together with sampling season and, for Fel $d 1$ models, cat numbers were included in the regression analyses. The number of older siblings and the number of residents in the home were included in each regression model in order to determine which had a stronger association with the level of the allergens.

Levels of $\operatorname{Der} p 1$ in the living rooms were independently associated with the season of measurement, visible damp, double glazing and fitted carpets, as well as with the number of residents in the home and inversely with the presence of $\geq 1$ smokers (table 5). Social class, after adjustment for these other factors, was not independently predictive of Der $p 1$ concentration. In a separate regression model, levels of this allergen in the child's bed increased significantly with the number of older siblings and were higher in older mattresses. Both regression models explained only a small amount of the variation in $\operatorname{Der} p 1\left(\mathrm{r}^{2}=0.09\right.$ and 0.04 , respectively).
Levels of Fel $d 1$ at both sites were strongly associated with the number of cats in the home (table 5). Levels found in the living room were independently related to having a carpet and the season of measurement, with the summer and autumn months generally having lower levels. In a separate regression model, levels in the child's bed were associated with older mattresses. Levels at both sites also decreased with increased crowding and displayed a significant downwards trend with social class. These models explained $44 \%$ and $26 \%$ of the variation, respectively.

\section{Discussion}

This report describes household concentrations of two common aeroallergens in a large, probably representative, series of homes in south-east England. The results provide

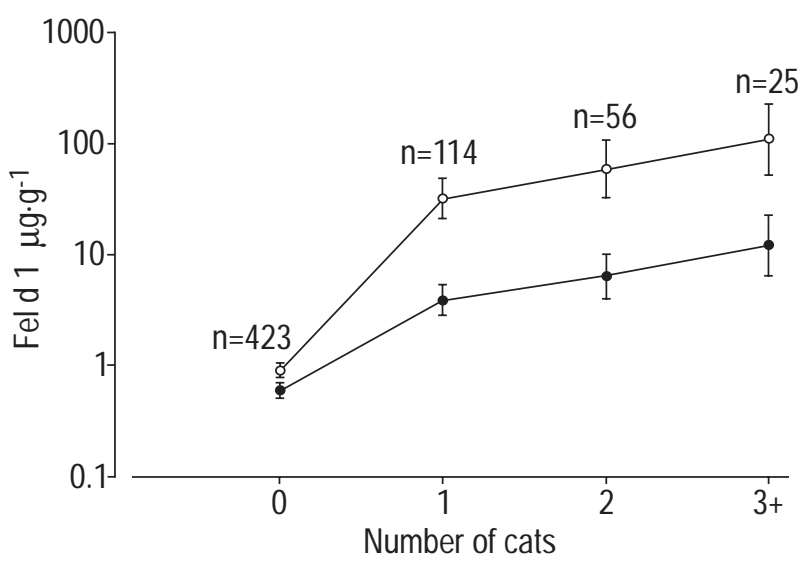

Fig. 2. - Cat allergen (Fel $d$ 1) levels in living room carpet $(\bigcirc)$ and child's bed (•) in homes with none, 1,2 and $\geq 3$ cats. Numerical values indicate number of households. Data presented as geometric mean $\pm 95 \%$ confidence interval. 
Table 5. - Results of stepwise regression analysis for determinants of indoor allergens

\begin{tabular}{|c|c|c|c|c|}
\hline & & Coefficient & SEM & p-value \\
\hline \multicolumn{5}{|c|}{ Living room levels of $\log _{\mathrm{e}}$ Der $p 1$} \\
\hline \multirow[t]{4}{*}{ Season } & Spring & Reference & & 0.001 \\
\hline & Summer & 0.34 & 0.22 & \\
\hline & Autumn & 0.80 & 0.22 & \\
\hline & Winter & 0.77 & 0.22 & \\
\hline \multicolumn{2}{|c|}{ Smoker at home } & -0.53 & 0.15 & 0.001 \\
\hline \multicolumn{2}{|c|}{ Visible damp } & 1.23 & 0.38 & 0.001 \\
\hline \multicolumn{2}{|c|}{ Double glazing } & 0.36 & 0.15 & 0.02 \\
\hline \multicolumn{2}{|c|}{ Fitted wall-to-wall carpets } & 0.79 & 0.39 & 0.04 \\
\hline \multirow{2}{*}{\multicolumn{5}{|c|}{$\begin{array}{l}\text { Number of residents } \\
\text { Child's bed levels of } \log _{\mathrm{e}} \text { Der } p 1\end{array}$}} \\
\hline & & & & \\
\hline \multicolumn{2}{|c|}{ "Old" mattress (>2 months old) } & 0.49 & 0.15 & 0.001 \\
\hline \multirow{2}{*}{\multicolumn{5}{|c|}{$\begin{array}{l}\text { Number of older siblings } \\
\text { Living room levels of } \log _{\mathrm{e}} \mathrm{Fel} d 1\end{array}$}} \\
\hline & & & & \\
\hline \multicolumn{2}{|c|}{ Number of cats } & 1.70 & 0.09 & $<0.001$ \\
\hline \multicolumn{2}{|c|}{ Number of residents } & -0.28 & 0.09 & 0.001 \\
\hline \multirow[t]{4}{*}{ Season } & Spring & Reference & & 0.02 \\
\hline & Summer & -0.54 & 0.26 & \\
\hline & Autumn & -0.34 & 0.24 & \\
\hline & Winter & 0.13 & 0.25 & \\
\hline \multicolumn{5}{|c|}{$\begin{array}{l}\text { Father's social class based on } \\
\text { occupation }\end{array}$} \\
\hline & I & \multicolumn{2}{|l|}{ Reference } & 0.02 \\
\hline & II & -0.38 & 0.36 & \\
\hline & IIIN & -0.66 & 0.38 & \\
\hline & IIIM & -0.89 & 0.34 & \\
\hline & IV & -0.97 & 0.36 & \\
\hline & V & -1.09 & 0.48 & \\
\hline Fitted w & all-to-wall carpets & 0.81 & 0.47 & 0.08 \\
\hline \multicolumn{5}{|c|}{ Child's bed levels of $\log _{\mathbf{e}} \mathrm{Fel} d 1$} \\
\hline Number & of cats & 0.97 & 0.08 & $<0.001$ \\
\hline Number & of residents & -0.27 & 0.09 & 0.002 \\
\hline \multicolumn{5}{|c|}{$\begin{array}{l}\text { Father's social class based on } \\
\text { occupation }\end{array}$} \\
\hline & I & Reference & & 0.07 \\
\hline & II & -0.09 & 0.34 & \\
\hline & IIIN & -0.39 & 0.37 & \\
\hline & IIIM & -0.59 & 0.33 & \\
\hline & IV & -0.30 & 0.35 & \\
\hline & V & -1.05 & 0.48 & \\
\hline "Old" m & attress (>2 months old) & 0.31 & 0.18 & 0.10 \\
\hline
\end{tabular}

*: Season: Spring: March-May; Summer: June-August; Autumn: September-November; Winter: December-February. Der $p$ 1: house dust mite allergen; Fel $d$ 1: cat allergen. Levels of allergen measured as $\mu \mathrm{g} \cdot \mathrm{g}^{-1}$.

an estimate of infant allergen exposures among a cohort of children who are being followed initially to the age of 6 yrs, allowing an examination of the nature and modifying influences of any relationships between early exposure and the development of asthma. Identical companion studies are underway in two other countries in Europe (two cohorts in Spain and one in Germany) with the aim of examining these relationships across a wide variation in domestic exposures and providing widely applicable results.

Single measurements of allergen concentrations in dust reservoirs are at best a proxy for infant exposures to common aeroallergens; however, the methodology for collecting and analysing such samples is relatively well standardized and, at least, allows the ordering of exposures into different categories of intensity. Like other studies, no important differences were found when concentrations were expressed per unit area rather than per unit weight of dust [6].
Differences in study populations mean that the present findings are not directly comparable to those from other household surveys. In this study, the homes of an unselected series of families with young children were examined, whereas other studies have usually selected homes by the presence of one or more inhabitants who were atopic or asthmatic. Nonetheless these results, showing that concentrations of Der $p 1$ are generally low but vary widely between British homes, are consistent with those from other surveys $[2,7]$. Almost half of the infants in this study lived in homes where the concentration of Der $p 1$ in the carpet or mattress was $>2 \mu \mathrm{g} \cdot \mathrm{g}^{-1}$, a proposed threshold for sensitization to this allergen, while $18 \%$ lived in homes where the concentration reached $\geq 10 \mu \mathrm{g} \cdot \mathrm{g}^{-1}$, a level reported to produce symptoms of wheeze in sensitized persons. Levels in New Zealand and Australia were reported to be very much higher $[6,8]$. There are fewer surveys of household $\mathrm{Fel} d 1$ concentrations; the present results are a little higher than those in Winnipeg, Canada [9] or in Sweden [10] but broadly similar to those measured in Manchester, UK [11]. An interesting comparison may be made with the exposures measured in the German Multicentre Allergy Study (MAS) cohort [1], a proportion of whom were recruited from a representative population. Allergen concentrations in that study were systematically lower than those described here; $55 \%$ of Ashford homes, for example, had levels of living room $\operatorname{Der} p 1$ above the 75th percentile for the MAS cohort $\left(>0.985 \mu \mathrm{g} \cdot \mathrm{m}^{-3}\right)$; and almost all (89\%) had Fel $d 1$ levels, at the same site, $>0.217$ $\mu \mathrm{g} \cdot \mathrm{m}^{-3}$. It is not clear to what extent these differences reflect the different extraction or assay techniques used in the two studies.

In Ashford, concentrations of Der $p 1$ in living room carpets were significantly higher where there was a fitted carpet, double-glazing or visible damp in the room and where measurements had been made in the autumn or winter. These features, in the main consistent with other surveys, probably reflect the underventilated, humid atmosphere favoured by Dermatophagoides spp. The seasonal variation in the present measurements echoes the findings of others in Scandinavia [10] and in Manchester, UK, where repeated measurements in 40 homes were also highest in October, although seasonal differences were small compared with those between different homes [7]. In the USA, seasonal variability has also been found, although with a different pattern [12]. Mattress levels of Der $p 1$ in Ashford were higher when the mattress was $>1$ month old, but there were no differences between plastic and other mattresses types; the questionnaire did not differentiate different types of synthetic coverings. An increase in asthma risk among 6 yr-old British children sleeping on synthetic pillows has been reported [13] and researchers in New Zealand have attributed this to higher accumulations of Der $p 1$ in synthetic pillows [14]. Although the present survey is not directly comparable, since allergen concentrations were measured in infant bedding, much of which was new, and the measured concentrations were systematically lower than those in New Zealand, this explanation could not be confirmed.

Levels of Fel $d 1$ in all sites were, unsurprisingly, strongly associated with the presence and number of cats in the home, and increased with the length of time for which a cat had been kept. As in other studies, cat allergen was also detected in most homes without cats $[10,15]$, reflecting the 
ubiquity of this allergen in communities with a high level of cat ownership. Allergen levels were higher where male cats were kept, although this difference was confined to long-haired breeds. WENTZ et al. [16] demonstrated the wide variability in allergen shedding between different cats and suggested, too, that male cats shed more than females. Other factors, which were not analysed, might include age, breed and behaviour. The higher levels measured in samples collected in the first 6 months of the year have also been reported in bedroom floors and mattresses in Winnipeg, Canada [9], and may reflect a complex interaction between ventilation within the home, the proportion of each day spent by cats indoors and the persistence of $\mathrm{Fel} \mathrm{d}$ 1 allergen in fittings and furnishings. However, no relationships were found between concentrations of $\mathrm{Fel} d 1$ and a variety of structural characteristics in the home.

The present study also examined allergen concentrations by a number of social or behavioural features, in particular those which have been reported to be important in the epidemiology of childhood atopy and asthma. Homes with $\geq 1$ smokers had lower concentrations of Der $p 1$, but not Fel $d$ 1, and similar findings were reported from homes in Berlin [17]. The reason for this is unclear but may reflect systematic differences in domestic ventilation. Conversely, MUNIR et al. [18], in a survey of 126 homes, reported higher levels of Der $p 1$ in the homes of smokers. The present results showed a trend towards increasing $\operatorname{Der} p 1$ concentrations in the living room carpets and mattresses of homes with more inhabitants and, as a corollary, in the mattresses of children with more older siblings. Given that many of the families in this cohort were likely to be incomplete, it is difficult to disentangle sibling and total resident numbers, although the latter appeared to be the stronger influence in the multiple regression. The relationship between Der $p 1$ concentrations and occupancy, reported elsewhere, may reflect the level of food sources available to house dust mites or other, complex behavioural influences. Intriguingly, an opposite relationship was observed for Fel $d 1$ levels, which fell both with household numbers and, independently, with social class. This pattern could not be accounted for by examining cat ownership.

Few differences in allergen concentrations were found between homes occupied by families with atopic parents and no differences in those where one or both parents, or the older sibling, had asthma. These findings suggest that, in this community, either there have been no systematic attempts by high-risk families to reduce household exposures to common aeroallergens, or they have been successful in already doing so. The lack of any important differences in obvious allergen reservoirs, such as carpeting in the living room and ownership of cats, suggests that this latter explanation is improbable.

These findings provide new data on domestic Fel $d 1$ levels and confirm a number of earlier observations with respect to determinants of household $\operatorname{Der} p 1$ exposures in Britain. The close and independent (but discordant) relationships between occupancy, season and (for $\mathrm{Fel} d$ 1) social class and allergen levels lead to the intriguing possibility that reported associations of atopy and allergic disease with family size, socioeconomic status and sibship may reflect not only differential tendencies to early infection, but also, perhaps, complex patterns of early allergen exposure.
Acknowledgements. The authors would like to thank the general practitioners in Ashford, $\mathrm{T}$. Bayley, M. Buckenham and B. Moffat.

\section{References}

1. Wahn U, Lau S, Bergmann R, et al. Indoor allergen exposure is a risk factor for sensitization during the first three years of life. J Allergy Clin Immunol 1997; 99: 763-769.

2. Sporik R, Holgate ST, Platts-Mills TAE, Cogswell JJ. Exposure to house-dust mite allergen (Der $p$ 1) and the development of asthma in childhood: a perspective study. $N$ Eng J Med 1990; 323: 502-507.

3. Cullinan P, Lowson D, Nieuwenhuijsen MJ, et al. Workrelated symptoms, sensitisation and estimated exposure in workers not previously exposed to laboratory rats. Occup Environ Med 1994; 51: 589-592.

4. Yunginer JW, Reed CE, O'Connell J, Melton LJ, O'Fallon WM, Silverstein MD. Epidemiology of asthma: incidence rates, 1964-1983.

5. Luczynska CM, Arruda LK, Platts-Mills TAE, Miller JD, Lopez M, Chapman MD. A two-site monoclonal antibody ELISA for the quantification of the major Dermatophagoides spp. allergens, Der $p 1$ and Der $f 1$. J Immunol Meth 1989; 118: 227-235.

6. Wickens K, Siebers R, Ellis I, et al. Determinants of house dust mite allergen in homes in Wellington, New Zealand. Clin Exp Allergy 1997; 27: 1077-1085.

7. Kalra S, Crank P, Hepworth J, Pickering CAC, Woodcock AA. Absence of seasonal variation in concentrations of the house dust mite allergen Der $p 1$ in South Manchester homes. Thorax 1992; 147: 928-931.

8. Peat JK, Tovey E, Mellis CM, Leeder SR, Woolcock AJ. Importance of house dust mite and alternaria allergens in childhood asthma: an epidemiological study in two climatic regions of Australia. Clin Exp Allergy 1993; 23: 812 820.

9. Quirce S, Dimich-Ward H, Chan $\mathrm{H}$, et al. Major cat allergen $(\mathrm{Fel} d \mathrm{~d}$ ) levels in the homes of patients with asthma and their relationship to sensitization to cat dander. Ann Allergy Asthma Immunol 1995; 75: 325-330.

10. Munir AKM, Einarsson R, Kjellman N-IM, Bjorksten B. Mite (Der $p$ 1, Der $f 1)$ and cat (Fel d 1) allergens in the homes of babies with a family history of allergy. Allergy 1993; 48: 158-163.

11. Custovic A, Simpson A, Pahdi H, Green RM, Chapman MD, Woodcock A. Distribution, aerodynamic characteristics and removal of the major cat allergen Fel $d 1$ in British homes. Thorax 1998; 53: 33-38.

12. Lintner TJ, Brame KA. The effects of season, climate, and air-conditioning on the prevalence of dermatophagoides mite allergens in household dust. $J$ Allergy Clin Immunol 1993; 91: 862-867.

13. Strachan DP, Carey IM. Home environment and severe asthma in adolescence: a population based case-control study. BMJ 1995; 311: 1053-1056.

14. Kemp T, Siebers R, Fishwick D, O'Grady G, Fitzharris P, Crane J. House dust mite allergen in pillows. BMJ 1996; 313: 916.

15. Wood RA, Eggleston PA, Lind P, et al. Antigenic analysis of household dust samples. Am Rev Respir Dis 1988; 137: 358-363.

16. Wentz PE, Swanson MC, Reed .CE. Variability of cat-allergen shedding. J Allergy Clin Immunol 1990; 85: 94-98.

17. Lau S, Luck W, Kulig M, Wahn U. Indoor allergen exposure and environmental tobacco smoke-exposure during the first five years of life. J Allergy Clin Immunol 1997; 99: S85.

18. Munir AKM, Bjorksten B, Einarsson R, et al. Mite allergens in relation to home conditions and sensitization of asthmatic children from three climatic regions. Allergy 1995; 50: 55-64. 